\title{
Stem Rust Spores Elicit Rapid RPG1 Phosphorylation
}

\author{
Jayaveeramuthu Nirmala, ${ }^{1}$ Tom Drader, ${ }^{2}$ Xianming Chen, ${ }^{3}$ Brian Steffenson, ${ }^{4}$ and Andris Kleinhofs ${ }^{1,2}$ \\ ${ }^{1}$ Department of Crop and Soil Sciences, ${ }^{2}$ School of Molecular Biosciences, and ${ }^{3}$ United States Department of Agriculture- \\ Agricultural Research Service and Department of Plant Pathology, Washington State University, Pullman 99164, U.S.A.; \\ ${ }^{4}$ Department of Plant Pathology, University of Minnesota, St. Paul 55108, U.S.A.
}

Submitted 14 January 2010. Accepted 11 July 2010.

\begin{abstract}
Stem rust threatens cereal production worldwide. Understanding the mechanism by which durable resistance genes, such as Rpg1, function is critical. We show that the RPG1 protein is phosphorylated within $5 \mathrm{~min}$ by exposure to spores from avirulent but not virulent races of stem rust. Transgenic mutants encoding an RPG1 protein with an in vitro inactive kinase domain fail to phosphorylate RPG1 in vivo and are susceptible to stem rust, demonstrating that phosphorylation is a prerequisite for disease resistance. Protein kinase inhibitors prevent RPG1 phosphorylation and result in susceptibility to stem rust, providing further evidence for the importance of phosphorylation in disease resistance. We conclude that phosphorylation of the RPG1 protein by the kinase activity of the pK2 domain induced by the interaction with an unknown pathogen spore product is required for resistance to the avirulent stem rust races. The pseudokinase pK1 domain is required for disease resistance but not phosphorylation. The very rapid phosphorylation of RPG1 suggests that an effector is already present in or on the stem rust urediniospores when they are placed on the leaf surface. However, spores must be alive, as determined by their ability to germinate, in order to elicit RPG1 phosphorylation.
\end{abstract}

The ability of plants to successfully defend themselves against invading pathogens depends on early perception of the pathogen and ability to initiate the appropriate signaling process to recruit and execute multicomponent defense responses. Extensive research in the last decade has revealed a sequence of biochemical events that appear to participate in the activation of plant disease resistance. The activation of defense responses in plants is initiated by host recognition of pathogen-associated molecular patterns (PAMPs). These are molecules that are conserved by specific classes of microbes and are often referred to as "general elicitors." They are recognized by specific pattern recognition receptors encoded by the host and mediate innate immunity. In case the basal defense system is overcome, plants have evolved a recognition system based on specific resistance (R) proteins that recognize specific pathogen effectors, which leads to a rapid defense response termed effector-triggered immunity (ETI) (Jones and Dangl 2006; Gohre and Robatzek 2008; de Wit et al. 2009; Stergiopoulos and de Wit 2009). Resistance or susceptibility of host plants to different races of a pathogen is determined, in many cases, by dominant $R$ genes in the plant and corresponding dominant avirulence (Avr) genes in the pathogen (Flor 1971). The Avr genes and their products have been characterized in a few well-studied pathogen-plant systems and have been shown to be elicitor mole-

Corresponding author: A. Kleinhofs; E-mail: andyk@wsu.edu cules that interact directly or indirectly with $R$ gene products (Mansfield 2009; Stergiopoulos and de Wit 2009). The $R$ genes, on the other hand, encode receptor molecules that detect the elicitor molecules either directly or indirectly via molecules they "guard" (Jones and Dangl 2006) or which act as "decoys" (van der Hoorn and Kamoun 2008). The decoy model proposes that the decoy protein acts solely to detect the pathogen effector and does not have a virulence function. Most $R$ genes cloned to date are of the nucleotide-binding site leucine-rich repeat (NBS-LRR) type but little is known about how the interaction of pathogen elicitors with host receptors activates signal transduction cascades that may involve protein phosphorylation, ion fluxes, reactive oxygen species (ROS), and other signaling events, leading to disease resistance in the plant host (Piedras et al. 1998; Blatt et al. 1999).

Receptors for fungal elicitors appear to reside either on the plasma membrane or in the cytoplasm of the plant cell (Yang et al. 1997; Hoefle and Huckelhoven 2008). Rapid changes at the cell surface that may be involved in the activation of inducible defense responses have been reported (Vera-Estrella et al. 1992). Plants activate their defenses against a variety of microorganisms by using a combination of signaling molecules, such as $\mathrm{K}+$ and $\mathrm{Cl}-$ efflux, as well as the production of $\mathrm{O}_{2}^{-}$, $\mathrm{H}_{2} \mathrm{O}_{2}$, and nitric oxide (Richberg et al. 1998), which induce significant changes on the plant cell surface. A crucial role for protein phosphorylation was suggested by the isolation of the Pto gene from tomato that encodes an S/T kinase (Martin et al. 1993). Subsequent cloning of the $\mathrm{Xa2} 1$ gene from rice, a gene that encodes an LRR transmembrane receptor-like kinase (Song et al. 1995); Pbs1 from Arabidopsis, encoding an S/T kinase (Swiderski and Innes 2001); Rpgl and Rpg5 from barley, which encode dual kinase domains and an NBS-LRR-S/T kinase, respectively (Brueggeman et al. 2002, 2008); and the Yr36 gene from wheat, which codes for a kinase START domain (Fu et al. 2009) strengthened this idea. In addition to the cloned genes, in vivo studies with phosphatase and protein kinase inhibitors have demonstrated that protein kinases and phosphatases play a critical role in the activation of early defense responses (Yang et al. 1997; Scheel 1998). Some downstream mitogen-activated protein kinases (MAPK) (Ligterink et al. 1997; Zhang and Klessig 1998b; Zhang et al. 1998; Romeis et al. 1999), calmodulin protein kinases (Romeis et al. 2000), syntaxin like proteins (Heese et al. 2005), and kinases involved in brassinosteroid signaling (Wang et al. 2005) are rapidly phosphorylated in response to specific or nonspecific elicitation. More recently, large-scale phosphoproteomics analyses have identified many proteins, which become rapidly phosphorylated upon exposure of the cells to the PAMP elicitor flagellin (Benschop et al. 2007; Nuhse et al. 2007). Proteins identified include kinases and other proteins potentially involved in disease resistance. Direct identification of phosphorylation 
sites in probable disease $R$ gene products such as the NBSLRR proteins was recently reported (Nakagami et al. 2010). Here, we report direct evidence for in vivo phosphorylation of a race-specific $\mathrm{R}$ protein, RPG1, and suggest that the phosphorylation results in activation of the stem rust disease resistance response.

The resurgence of stem rust on wheat and barley, caused by Puccinia graminis f. sp. tritici, via the highly virulent race TTKSK (also known as Ug99) and its variants has brought renewed interest in stem rust $R$ genes and their function. The barley Rpgl gene has conferred durable resistance against many $P$. graminis f. sp. tritici races for over 60 years (Steffenson 1992; Kleinhofs et al. 2009). The Rpgl gene was cloned by a map-based approach (Brueggeman et al. 2002) and validated by haplotype sequencing and stable transformation of a susceptible cultivar, Golden Promise, which was rendered completely resistant (Horvath et al. 2003). Rpg1 is a novel disease $R$ gene encoding a kinase with a pseudokinase domain (pK1) and an active kinase domain (pK2), both of which are required for disease resistance (Nirmala et al. 2006). The RPG1 protein autophosphorylates in vitro but its in vivo significance is not known. However, failure to autophosphorylate under in vitro conditions correlated with lack of RPG1 protein degradation in vivo (Nirmala et al. 2007) and disease susceptibility (Nirmala et al. 2006, 2007).

Therefore, to understand how RPG1 perceives the signal from the fungus, we investigated the in vivo phosphorylation status of RPG1 upon inoculation with the rust pathogen. Here, we show that RPG1 is rapidly phosphorylated only in response to avirulent but not virulent rust fungus spores and that this phosphorylation is required for disease resistance. The rapidity
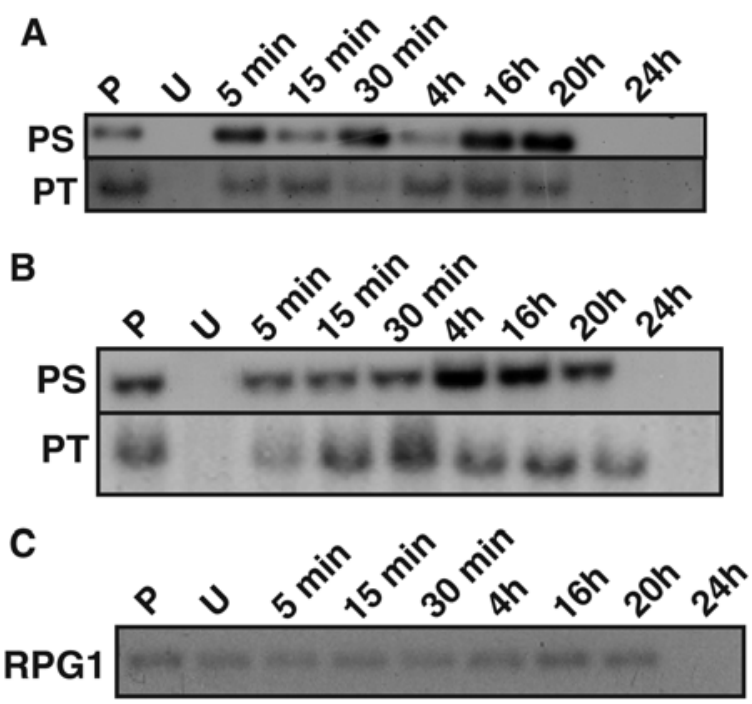

Fig. 1. Western blots showing that the RPG1 protein is phosphorylated within 5 min postinoculation with the avirulent Puccinia graminis $\mathrm{f} . \mathrm{sp}$. tritici race MCCF spores. The RPG1 protein is retained in the phosphorylated state for up to $20 \mathrm{~h}$ after inoculation, at which time it is degraded, as we have previously demonstrated (Nirmala et al. 2007). The RPG1 protein is not phosphorylated in the uninoculated sample (U). A, Total seedling leaf proteins were precipitated with either phosphoserine or phosphothreonine antibodies and were separated on polyacrylamide gels, blotted, and visualized with an RPG1-specific antibody. B, Total seedling leaf proteins were precipitated with an RPG1-specific antibody, processed as above, and visualized with phosphoserine or phosphthreonine antibodies separately. C, Total seedling leaf proteins were precipitated with an RPG1-specific antibody, processed as above, and visualized with RPG1-specific antibodies to demonstrate the presence of the RPG1 protein in the extracts. $\mathrm{P}=$ in vitro phosphorylated RPG1 protein positive control; $\mathrm{U}=$ uninoculated control; $\mathrm{PS}=$ phosphoserine antibody; $\mathrm{PT}=$ phosphothreonine antibody. of the phosphorylation and apparent autophosphorylation suggest that this is an early signal needed to initiate a cascade of biochemical events leading to activation of the defense response and disease resistance.

\section{RESULTS}

RPG1 protein is phosphorylated within 5 min postinoculation with stem rust race MCCF spores.

To understand how RPG1 perceives the signal from the stem rust fungus, we analyzed the in vivo phosphorylation status of RPG1 upon inoculation with the pathogen. Total phosphorylated proteins were precipitated with phosphoserine or phosphothreonine-specific antibodies and tested with RPG1-specific antibodies in a Western blot. To eliminate the possibility that unphosphorylated RPG1 was co-precipitated with phosphorylated proteins, the total proteins were also first immunoprecipitated with the RPG1 antibody and then tested with phosphoserine or phosphothreonine-specific antibodies. In both cases, the results showed that RPG1 was not phosphorylated in the absence of the fungus but became rapidly phosphorylated within only $5 \mathrm{~min}$ after the avirulent $P$. graminis f. sp. tritici race $\mathrm{MCCF}$ spores were delivered on the leaf surface of the resistant cv. Morex (Fig. 1). To eliminate the possibility that lack of the RPG1 protein phosphorylation prior to exposure of the leaf to avirulent rust spores was due to in vitro dephosphorylation during extraction, we included phosphatase inhibitors in the protein extraction buffer. The RPG1 phosphorylated state was maintained past $20 \mathrm{~h}$ postinoculation (Fig. 1), after which it was degraded in cv. Morex as previously reported (Nirmala et al. 2007). RPG1 was also phosphorylated in the moderately resistant cv. Beacon, highly resistant cvs. Chevron and Q21861 (Fig. 2), and the highly resistant Rpg1 transgene line (GP/Rpg1T1) (Fig. 3). RPG1 was also phosphorylated in two lines that produce the RPG1 protein but are susceptible to stem rust, demonstrating that, although phosphorylation is important for disease resistance, it is not sufficient by itself. The two lines are the rprl mutant (Zhang et al. 2006), which has an intact Rpg1, and OSU6 (PBI004-7-0-015 accession no. 8321), a wild barley accession with a GTT insertion in the Rpgl gene resulting in an $\mathrm{S}$ to $\mathrm{R}$ amino acid substitution plus an F insertion (Fig. 2) (Brueggeman et al. 2002; Mirlohi et al. 2008). RPG1 was not phosphorylated when mock inoculated with talc only.

\section{RPG1 is phosphorylated only when plants are inoculated with viable but not \\ with unviable race MCCF urediniospores.}

To determine whether the avirulent stem rust urediniospores need to be viable, we tested the ability of both viable and unviable spores of $P$. graminis $\mathrm{f}$. sp. tritici race MCCF to elicit RPG1 phosphorylation. The results revealed that RPG1 is specifically phosphorylated only when inoculated with viable spores, determined to be capable of germinating on $2 \%$ water agar plates, but not by unviable spores, which failed to germinate on $2 \%$ water agar after exposure to room temperature for 3 months. (Fig. 4).

\section{RPG1 is phosphorylated when plants are inoculated with avirulent but not virulent races of the stem rust fungus or nonspecific pathogens.}

Urediniospores from avirulent and virulent $P$. graminis $\mathrm{f}$. sp. tritici races were used to inoculate leaves of cv. Morex in order to determine whether or not their ability to phosphorylate RPG1 was race specific. RPG1 was rapidly phosphorylated when plants were inoculated with the avirulent races MCCF 
(Fig. 1), SCCL-C7a, and HKHJ but not with the virulent $P$. graminis $\mathrm{f}$. $\mathrm{sp}$. tritici race $\mathrm{QCCJ}$ or a virulent $P$. graminis $\mathrm{f} . \mathrm{sp}$. secalis (rye stem rust) isolate $92-\mathrm{MN}-90$ (Fig. 5). Further tests for specificity were conducted with the virulent but not RPG1specific pathogens $P$. striiformis f. sp. hordei (barley stripe rust) and Cochliobolus sativus, the spot blotch pathogen. Barley cv. Morex is susceptible to stripe rust but moderately resistant to spot blotch. These pathogens did not elicit phosphorylation of RPG1 (Fig. 5). These results demonstrate that the in vivo phosphorylation of RPG1 protein is a highly specific response initiated between the Rpgl gene product and a thus-farunknown fungal effector or an AvrRpgl gene product and not with other $A v r$ gene products carried by other stem rust isolates or nonspecific pathogens.
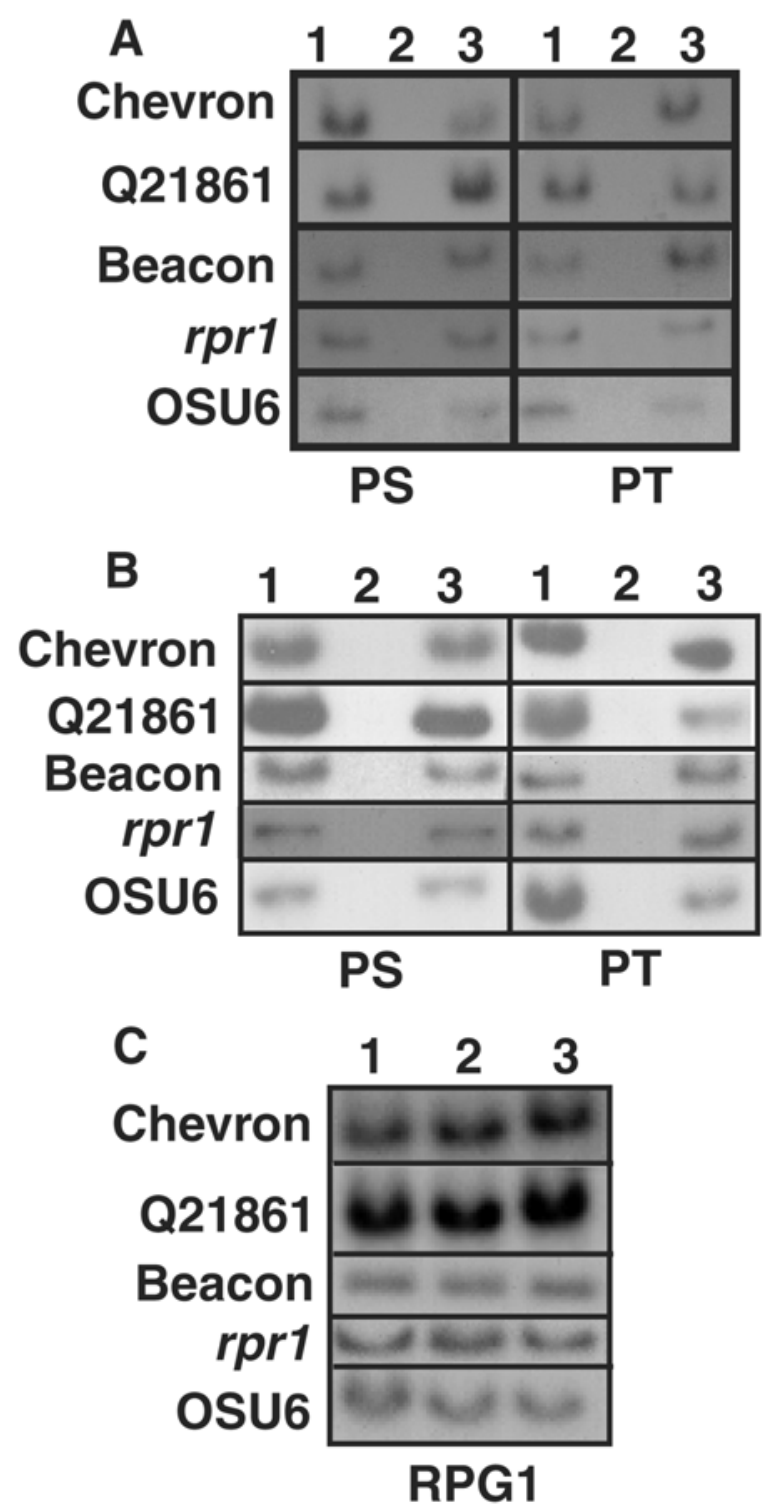

Fig. 2. Western blots showing that the RPG1 protein is phosphorylated postinoculation with the avirulent Puccinia graminis f. sp. tritici race MCCF spores in Rpgl-gene-containing barley cultivars. Total seedling leaf proteins were precipitated with either $\mathbf{A}$, phosphoserine or phosphothreonine antibodies or $\mathbf{B}$ and $\mathbf{C}$, RPG1-specific antibodies and were separated on polyacrylamide gels, blotted, and visualized with an RPG1-specific antibody. Bands were visualized with either $\mathbf{A}$ and $\mathbf{C}$, RPG1-specific antibody or $\mathbf{B}$, phosphoserine or phosphothreonine antibodies separately. Lane 1, in vitro phosphorylated RPG1 protein positive control; lane 2, uninoculated control; lane 3, 5 min postinoculation. PS = phosphoserine antibody; PT = phosphothreonine antibody.
Phosphorylation of RPG1 is correlated with disease resistance.

To determine whether the in vivo phosphorylation of RPG1 is required for disease resistance, we tested the ability of two different transgenic loss-of-function mutants, GP/Rpg1-pK1 (KK152, 153NQ) and GP/Rpg1-pK2 (KK461, 462NQ), for their response to inoculation with the avirulent $P$. graminis $\mathrm{f}$. $\mathrm{sp}$. tritici race MCCF. The catalytically inactive GP/Rpg1-pK2 domain mutant (KK461, 462NQ), incapable of autophosphorylating RPG1 in vitro, also failed to phosphorylate in vivo upon inoculation with rust spores, suggesting that RPG1 autophosphorylation in vivo is required for disease resistance (Fig. 3). The GP/Rpgl-pK2 and GP/Rpgl-pK1 mutants were previously shown to be susceptible to stem rust and to express the RPG1 protein (Nirmala et al. 2006, 2007). The RPG1 pK1 domain mutant (KK152/153NQ), capable of being phosphorylated in vitro, is phosphorylated in vivo (Fig. 3) but is susceptible to rust, suggesting that this domain functions downstream in the resistancesignaling pathway. To further confirm the role of RPG1 phosphorylation in disease resistance, we tested seven different serine-threonine protein kinase inhibitors for their ability to prevent
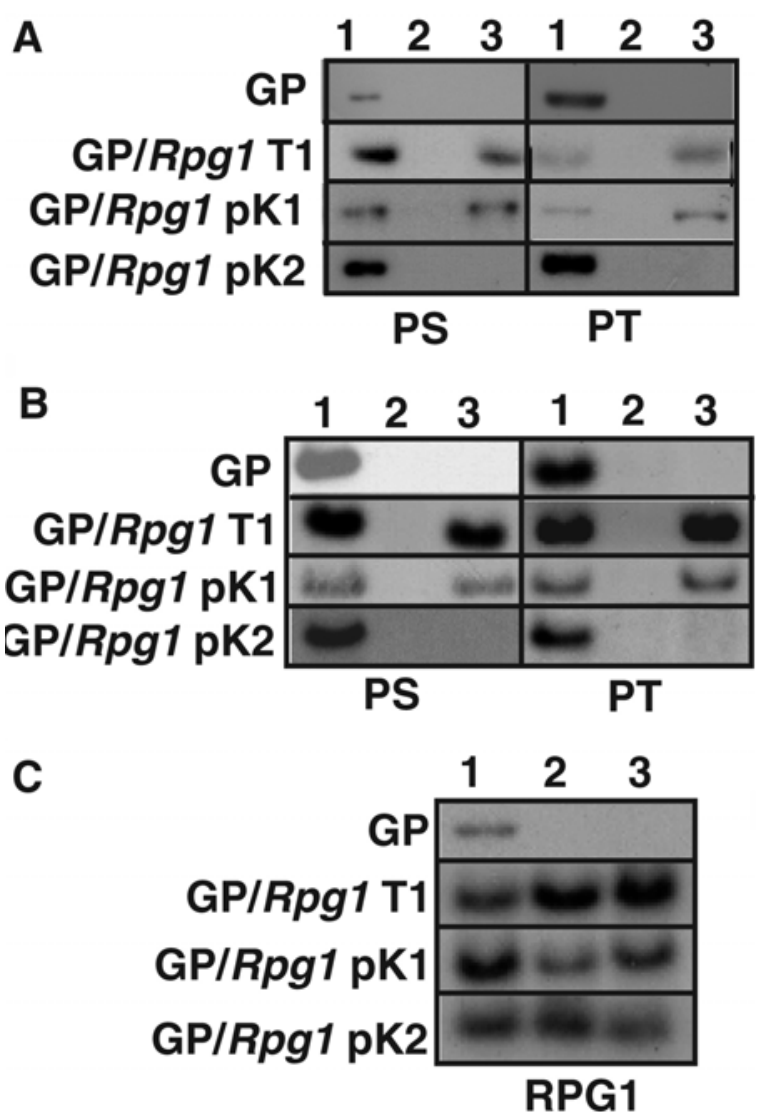

Fig. 3. Western blots showing that RPG1 phosphorylation is dependent on a functional protein kinase 2 domain. The RPG1 protein fails to become phosphorylated in response to inoculation with Puccinia graminis f. sp. tritici race MCCF in the susceptible transgenic mutant GP/Rpg1 pK2 (KK461/462NQ) whereas the RPG1 protein produced by the susceptible transgenic mutant GP/Rpg1 pK1 (KK152/153NQ) and the highly resistant wild-type Rpg1 transgene GP/Rpg1T1 are phosphorylated. Total seedling leaf proteins either $\mathbf{A}$, were precipitated with phosphoserine or phosphothreonine antibodies and the bands visualized with RPG1-specific antibody or B, were precipitated with RPG1-specific antibody and the bands visualized with phosphoserine or phosphthreonine antibodies separately or C, with RPG1-specific antibodies. Lane 1, in vitro phosphorylated RPG1 protein positive control; lane 2, uninoculated control; lane 3, 15 min postinoculation. Golden Promise (GP) does not have an RPG1 protein and a protein cross-reacting with the RPG1 antibody is not detected. PS = phosphoserine antibody; PT = phosphothreonine antibody. 
in vivo phosphorylation of RPG1 and their effect on disease reaction to $P$. graminis $\mathrm{f}$. $\mathrm{sp}$. tritici race $\mathrm{MCCF}$ on $\mathrm{cv}$. Morex. All seven kinase inhibitors (identified in Figure 6) inhibited phosphorylation of RPG1 and converted the incompatible reaction to a compatible reaction in the resistant cv. Morex (Fig. 6).

\section{DISCUSSION}

The barley stem rust resistance protein RPG1 is phosphorylated within 5 min after inoculating the leaves with hydrated spores from avirulent but not virulent stem rust races or nonspecific pathogens. The RPG1 phosphorylated state is maintained for $20 \mathrm{~h}$ postinoculation, after which it is degraded as previously demonstrated (Nirmala et al. 2007). The speed at which RPG1 is phosphorylated is remarkable because obvious spore germination does not take place until approximately 30 min after they are placed on the leaf surface and provided with free moisture. This very rapid pathogen recognition suggests that it is a primary event that sets the host disease resistance signaling pathway in action. Because the 5-min time frame is well before the rust spores have time to germinate and infect the host cells, we postulate that an unknown effector may already be present on or in the spore, waiting to sense the presence of a suitable host surface. However, metabolic activity seems to be required because unviable spores failed to elicit the phosphorylation response. Research with the flax rust fungus has shown that AVR proteins are synthesized within haustoria and transported into the host cytoplasm, where they interact with the $\mathrm{R}$ proteins and activate the downstream signaling cascades (Dodds et al. 2004; Catanzariti et al. 2006). Stem rust appressoria formation and penetration of the stomata takes place approximately 12 to $24 \mathrm{~h}$ postinoculation and obvious differences between resistant (Rpgl) and susceptible (rpgl) cultivars were not observed during this time (Sellam and Wilcoxson 1976) (B. Steffenson, unpublished). Thus, Rpg1mediated resistance to stem rust does not become visibly (via microscope) functional until some time after 12 to $24 \mathrm{~h}$ postinoculation and may correlate with haustoria formation. Our observations demonstrate that the RPG1 protein recognizes the avirulent spores long before haustoria formation.

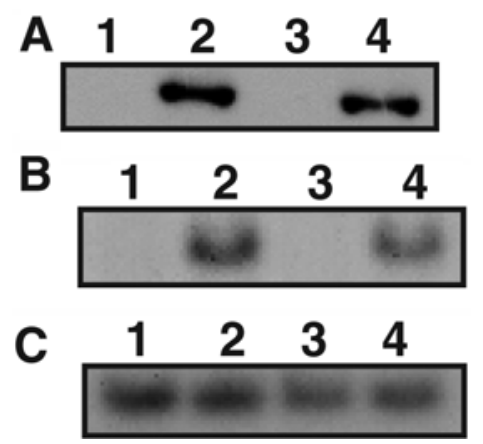

Fig. 4. Western blots showing that RPG1 is phosphorylated only when leaves are inoculated with viable but not with unviable spores of Puccinia graminis f. sp. tritici race MCCF in cv. Morex. Total seedling leaf proteins were precipitated and were separated on polyacrylamide gels, blotted, and visualized with an RPG1-specific antibody. A, Precipitated with either phosphoserine or phosphothreonine antibodies and the bands visualized with RPG1-specific antibody. B and C, Precipitated with RPG1-specific antibody and the bands visualized with $\mathbf{B}$, phosphoserine or phosphothreonine antibodies separately or C, RPG1-specific antibodies. Lanes 1 and 3, total proteins immunoprecipitated from the plants inoculated with unviable spores, respectively; lanes 2 and 4: total proteins immunoprecipitated from plants inoculated with viable spores, respectively (all at 30 min postinoculation). Unviable spores are defined as not capable of germination on $2 \%$ water agar plates and were generated by storing the spores at room temperature for 3 months.
This recognition leads to RPG1 phosphorylation and disease resistance, as demonstrated by mutant and inhibitor studies described herein. It is possible that a mechanism of resistance different from AVR protein recognition exists or that the specific AVR protein may already be present in the spores and is released into the plant cells and detected by the RPG1 R protein. In the flax rust, $A v r$ genes were primarily expressed at the RNA level only in infected tissues, probably in haustoria and the mycelium, except for AvrM, where they were also expressed in in-vitro-germinated spores. Among the Avr genes analyzed, expression was not detected in ungerminated spores (Dodds et
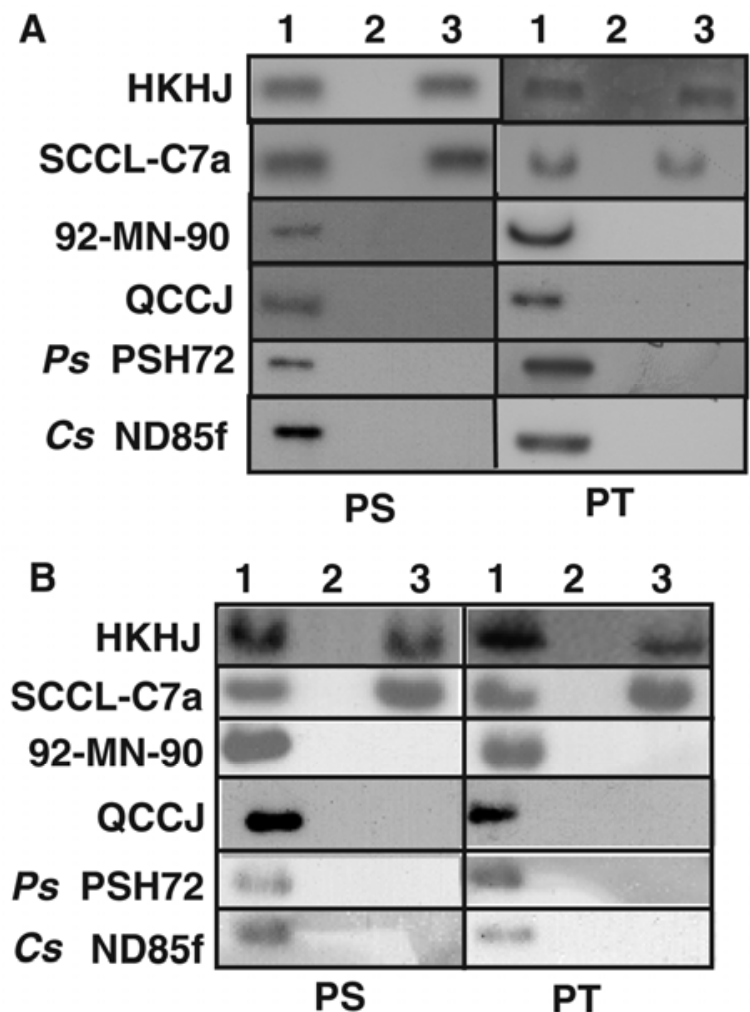

C

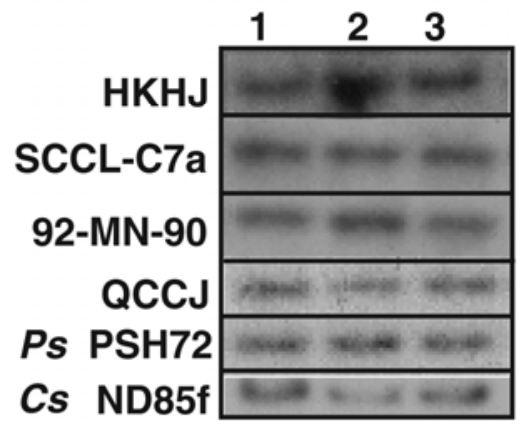

RPG1

Fig. 5. Western blots showing that RPG1 is phosphorylated upon inoculation with avirulent but not virulent races of the stem rust fungus or nonspecific pathogens in cv. Morex. A, Total seedling leaf proteins were precipitated with either phosphoserine or phosphothreonine antibodies and the bands visualized with RPG1-specific antibody or $\mathbf{B}$, protein was precipitated with RPG1-specific antibody and the bands visualized with phosphoserine or phosphothreonine antibodies separately or C, with RPG1-specific antibodies. Avirulent Puccinia graminis f. sp. tritici races HKHJ and SCCL-C7a, virulent $P$. graminis f. sp. secalis isolate $92-\mathrm{MN}-90$ and $P$. graminis f. sp. tritici race QCCJ, RPG1 nonspecific pathogens barley stripe rust race - Ps PSH72, and spot blotch isolate Cs ND85f. Lane 1, in vitro phosphorylated RPG1 protein positive control; lane 2, uninoculated control; lane 3,15 min postinoculation. $\mathrm{PS}=$ phosphoserine antibody; $\mathrm{PT}=$ phosphothreonine antibody. 
al. 2004; Catanzariti et al. 2006). These experiments suggest that there is variation in the expression pattern among the different $A v r$ genes and they do not exclude the possibility that stored AVR protein may be present in ungerminated spores.

Rpg1 mRNA and protein are present in the barley leaf epidermal cells at levels considerably higher than those found elsewhere in the leaf (Rostoks et al. 2004) (J. Nirmala, unpublished). A small but significant amount of RPG1 protein is also present in the plasma membrane (Nirmala et al. 2006). The plant plasma membrane is expected to be the initial site where elicitor-receptor interaction is most likely to take place; therefore, it is possible that rust elicitors interact or mediate via the plasma-membrane-associated RPG1. The RPG1 protein structure and some functional aspects are strikingly similar to the animal Janus kinases (JAK) (O'Shea and Leonard 1998). JAK family members and their functions are diverse. Briefly, they function via a pathway whereby transmembrane receptors are activated by external effectors which, in turn, activate the JAK. JAK proteins activate transcription factors which migrate to the nucleus and activate the appropriate response genes (Aaronson and Horvath 2002). It would be naive to expect that RPG1 will function in a very similar manner but the JAK pathway does provides a valuable model for testing ideas.

The role of RPG1 phosphorylation in disease resistance is underscored by the observation that the highly susceptible Rpg 1 transgenic pK2 mutant, which encodes an RPG1 protein that fails to phosphorylate in vitro, also fails to phosphorylate in vivo upon inoculation with the avirulent $P$. graminis $\mathrm{f}$. $\mathrm{sp}$. tritici race MCCF. This demonstrates that RPG1 is a very early or initial recipient of the fungal effector, and the observation that the inactive kinase mutant $\mathrm{pK} 2$ is not phosphorylated in vivo and does not confer disease resistance strongly suggests that RPG1 autophosphorylates and this reaction is required for disease resistance. Additional evidence for the role of phosphorylation in the stem rust resistance-signaling pathway comes from the use of kinase inhibitors (Fig. 6), which most likely inhibit other host kinases besides RPG1 but also prevented the phosphorylation of RPG1 and converted the incompatible reaction to a compatible reaction in the resistant $\mathrm{cv}$. Morex.

The pK2 domain of RPG1 is involved in phosphorylation and disease resistance. However, the specific role of the $\mathrm{pK} 1$ domain is not clear, despite its requirement for disease resistance. Two susceptible Rpg1 pK1 mutants with KK152/153NQ substitutions and a GTT insertion encode RPG1 proteins that are phosphorylated. The Rpgl gene with a GTT insertion, encoding a protein with $\mathrm{S}$ to $\mathrm{R}$ amino acid substitution plus an $\mathrm{F}$ insertion (Brueggeman et al. 2002; Mirlohi et al. 2008), is also degraded just like wild-type RPG1 (J. Nirmala, unpublished). Thus, although RPG1 phosphorylation and degradation are essential for RPG1-mediated stem rust resistance, it is not sufficient. We speculate that the $\mathrm{pK} 1$ domain acts downstream of these events and is perhaps involved in protein-protein interac-

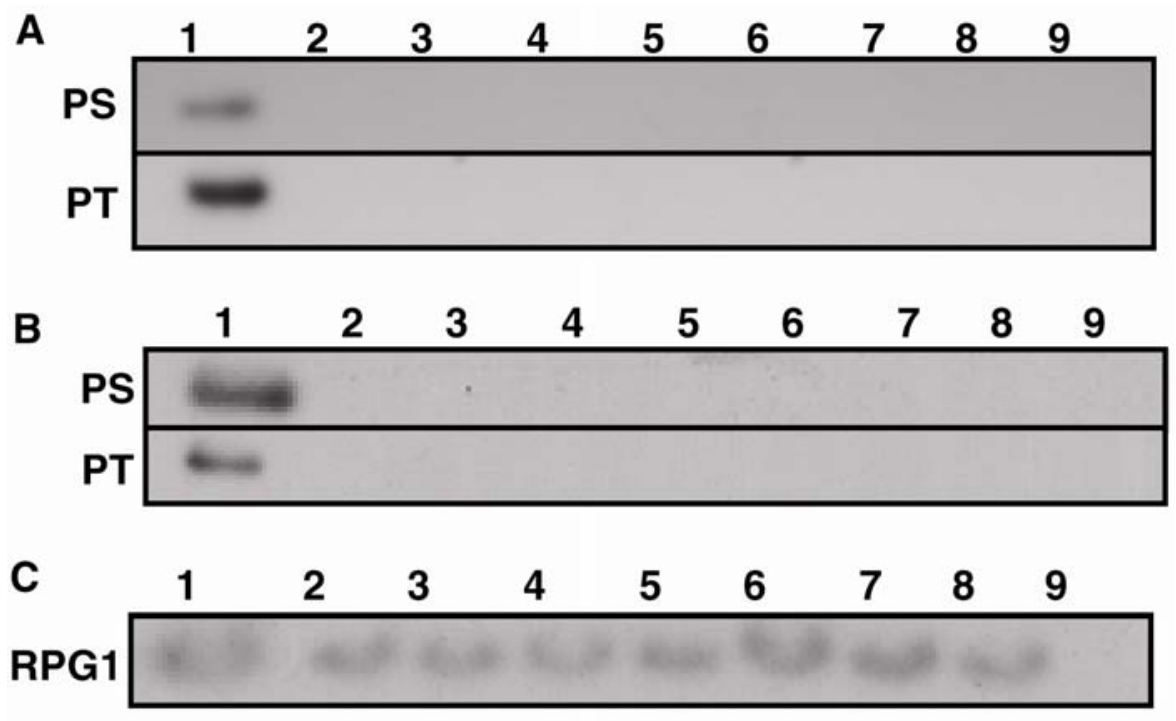

D

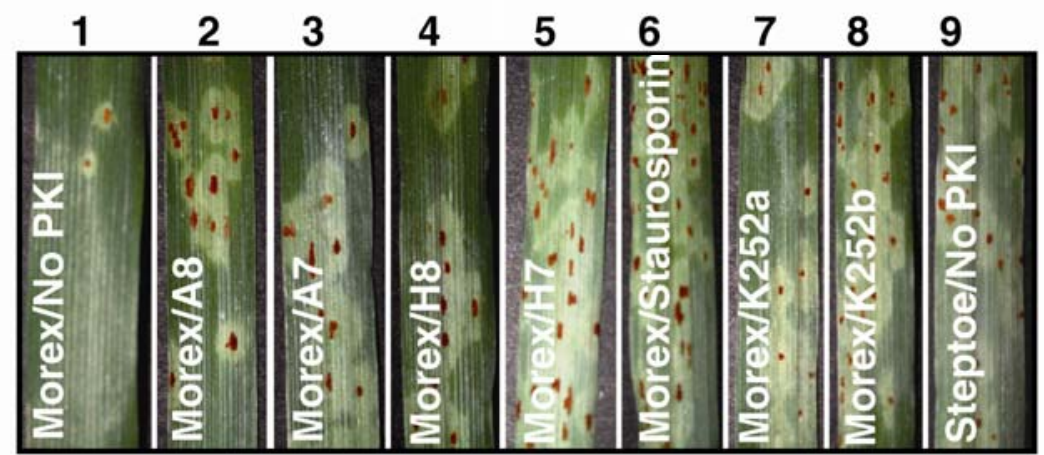

Fig. 6. Seven different protein kinase inhibitors (PKI) prevent phosphorylation of RPG1 and convert the incompatible disease reaction to compatible in Rpgl-containing cv. Morex in response to Puccinia graminis f. sp. tritici race MCCF. A, Total seedling leaf proteins were precipitated with either phosphoserine or phosphothreonine antibodies and the Western blot bands visualized with RPG1 specific antibody or B and C, proteins were precipitated with RPG1 specific antibody and the bands visualized with B, phosphoserine or phosphothreonine antibodies separately or C, RPG1-specific antibodies. D, Disease phenotype. PKI = protein kinase inhibitor. Lanes 1-9: no. PKI, A8, A7, H8, H7, Staurosporin, K252a, K252b, and Steptoe no PKI, respectively. Cv. Steptoe does not produce an RPG1 protein. 
tions essential for the disease resistance response. These putative proteins remain to be identified.

Phosphorylation is one of the most widespread post-translational modifications, and multiple cellular processes are regulated by phosphorylation and dephosphorylation (Durek et al. 2010; Grimsrud et al. 2010; Nakagami et al. 2010). However, its role in $R$-gene activation or function has not been widely investigated to date. Rapid and transient protein phosphorylation in parsley and tomato cell suspension cultures has been reported (Dietrich et al. 1990; Felix et al. 1991). Protein kinase inhibitors such as K-252a and staurosporin block these elicitor-induced changes in phosphorylation and prevent the induction of plant defense responses. Protein phosphorylation was also required for early steps in CF9-dependent AVR9-activated defense systems and tobacco-Tobacco mosaic virus- $N$ interaction. Known proteins phosphorylated include the MAPK (or orthologues) MPK3 and MPK6, WIPK and SIPK, and tobacco syntaxin NtSyp121 (Zhang and Klessig 1998a; Zhang et al. 1998; Heese et al. 2005). One of the most extensively investigated defensesignaling pathway in plants is the flagellin activated MAPK pathway in Arabidopsis (Asai et al. 2002). Flagellin, a highly conserved protein found in bacterial flagella, is recognized as a PAMP by FLS2 (LRR receptor kinase flagellin-sensitive 2) that activates a MAPK cascade conferring resistance to bacterial and fungal pathogens (Asai et al. 2002). FLS2 has also been shown to interact with BAK1 (BRI1-associated receptor kinase), an LRR kinase that regulates the brassinosteroid receptor kinase BRI1 (Nam and Li 2002; Chinchilla et al. 2007). The BAK1/FLS2 interaction is very rapid (within the first minutes of flagellin exposure) and results in enhanced pathogen resistance, presumably through innate immunity (Chinchilla et al. 2007). These observations are of interest to the understanding of the RPG1-mediated pathogen resistance, although the signaling we describe here seems to be very specific to the avirulent stem rust races and not due to PAMPs.

The majority of plant pathogen receptor genes cloned to date are of the NBS-LRR type (Jones and Dangl 2006); however, receptor-like kinases or proteins such as XA21 and CF9 are also known to recognize specific AVR-type molecules and confer resistance (Song et al. 1995; Hammond-Kosack and Jones 1997). The RPG1 protein has similarity to receptor-like protein kinases, although it lacks any known receptor domain (Brueggeman et al. 2002). This suggests that RPG1 might interact with other receptor molecules at the cell surface; however, at this time, we do not have any evidence for or against that hypothesis.

To summarize, this is the first demonstration of a very rapid and specific $\mathrm{R}$ protein phosphorylation upon detection of a pathogenic fungus. The model we currently favor is that RPG1 acts as a receptor or in conjunction with a receptor, perceives the initial signal from the rust pathogen, and phosphorylates itself. This phosphorylation initiates the downstream signaling events, eventually resulting in the degradation or turn over of RPG1 by the proteosomal pathway. The relationship between the phosphorylation and degradation is not clear. It is possible that both function in concert to provide maximum disease resistance. Another possibility is that the degradation of RPG1 might be the end result rather than a prerequisite for the resistance reaction. It is possible that the degradation of RPG1 is to prevent runaway hypersensitive response, as has been suggested in the case of the Arabidopsis RPM1 R protein degradation (Boyes et al. 1998).

The mechanism by which the fungus is detected on the leaf surface is under investigation. Presumably, it is a compound which is found on or in the dormant spores and is activated by uptake of moisture or interaction with something on the leaf surface. At this point, we do not have enough information to speculate about this process.

\section{MATERIALS AND METHODS}

\section{Plant materials.}

Barley lines were grown in growth chambers in plastic pots containing potting mix with a day and night temperature of $21 \pm 1$ and $18 \pm 1^{\circ} \mathrm{C}$, respectively, and a 16-h photoperiod provided by cool fluorescent tubes $\left(525 \mu \mathrm{E} / \mathrm{m}^{2}\right)$. The cultivars or lines used are described in Table 1.

\section{Stem rust inoculation.}

Seven-day-old plants were inoculated with urediniospores of avirulent (MCCF, SCCL-C7a, or HKHJ) or virulent (QCCJ) $P$. graminis f. sp. tritici races or with virulent $P$. graminis f. sp. secalis isolate $92-\mathrm{MN}-90$. Controls were grown under the

Table 1. Description of barley cultivars and mutants used in RPG1 phosphorylation assays

\begin{tabular}{|c|c|c|c|c|}
\hline \multirow[b]{2}{*}{ Barley genotypes ${ }^{b}$} & \multirow[b]{2}{*}{ Stem rust phenotype ${ }^{c}$} & \multicolumn{3}{|c|}{ RPG1 $^{\mathbf{a}}$} \\
\hline & & Protein $^{d}$ & Phosphorylation $^{\mathrm{e}}$ & Degradation $^{f}$ \\
\hline Morex & Resistant & + & + & + \\
\hline Chevron & Highly resistant & + & + & + \\
\hline Q21861 & Highly resistant & + & + & + \\
\hline Beacon & Moderately resistant & + & + & + \\
\hline OSU6 & Susceptible & + & + & + \\
\hline rprl & Susceptible & + & + & + \\
\hline GP & Susceptible & NP & NP & NP \\
\hline GP/Rpg1-T1 & Highly resistant & + & + & + \\
\hline GP/Rpg1-pK1 & Susceptible & + & + & - \\
\hline GP/Rpg1-pK2 & Susceptible & + & - & - \\
\hline Steptoe & Susceptible & NP & NP & NP \\
\hline
\end{tabular}

${ }^{a} \mathrm{NP}=$ no protein.

b Morex, Chevron, Q21861, Beacon, Golden Promise (GP), and Steptoe are barley cultivars and lines. OSU6 (PBI004-7-0-015 accession no. 8321) is a wild barley accession with a GTT insertion in the Rpgl gene resulting in an S-R amino acid substitution plus an F insertion (Mirlohi et al. 2008). rprl is a deletion mutant of a gene required for Rpgl function (Zhang et al. 2006). GP/RpglT1 is a single-copy transgenic Rpg1 line in GP genomic background (Horvath et al. 2003). GP/Rpg1pK1 is a pseudokinase domain 1 mutant transgene (KK152/153NQ) in GP background (Nirmala et al. 2006). GP/Rpg1pK2 is a kinase domain 2 mutant transgene (KK461/462NQ) in GP background (Nirmala et al. 2006).

${ }^{c}$ Phenotypes have been previously determined (Steffenson 1992; Brueggeman et al. 2002; Horvath et al. 2003; Nirmala et al. 2006; Zhang et al. 2006) and were confirmed in this study.

${ }^{\mathrm{d}}$ Presence or absence of RPG1 protein has been previously determined (Nirmala et al. 2006) and was confirmed in this study. Cv. Steptoe has a defective Rpg1 gene and does not produce detectable RPG1 protein. GP does not have the Rpg1 gene and does not produce RPG1.

e Phosphorylation of RPG1 protein was determined in this study.

${ }^{\mathrm{f}}$ Degradation of RPG1 protein has been previously determined (Nirmala et al. 2007) (J. Nirmala, unpublished). 
same conditions but were mock inoculated only with talc. Plants to be assayed for rust infection were inoculated with the rust urediniospores at a rate of $0.25 \mathrm{mg} / \mathrm{plant}$ with talc as a carrier (Sigma-Aldrich, St. Louis) at a 1:20 ratio. After inoculation, the plants were misted and placed in the dark under humid conditions for $22 \mathrm{~h}$. Thereafter, plants were exposed to light and misted periodically. After $4 \mathrm{~h}$ at this regime, the misting was stopped and the leaves were left to dry slowly. When the leaf surfaces were completely dry, plants were moved back to the growth chambers at $24^{\circ} \mathrm{C}$ and $100 \%$ relative humidity. Plants were phenotyped 14 days after rust inoculation.

For phosphorylation assays, the plants were inoculated with urediniospores or mock inoculated as above. After inoculation, the plants were lightly misted with water and immediately placed in a dark, humid chamber and timing started. This was done one plant at a time in order to make it as reproducible as possible. The elapsed time between inoculation, misting, and placing the plants in a moist chamber was approximately $30 \mathrm{~s}$. Leaf samples were taken at the indicated time points and immediately frozen in liquid nitrogen. The frozen material in liquid nitrogen was brought to the laboratory and prepared for protein analysis as described below.

\section{Stripe rust inoculation.}

Seedlings were inoculated with barley stripe rust $(P$. striiformis f. sp. hordei), race PSH-72. Urediniospores were mixed with talc (Sigma-Aldrich) at a 1:20 ratio and spread on the leaves. The inoculated plants were kept in a dew chamber at $10^{\circ} \mathrm{C}$ in the dark for $24 \mathrm{~h}$ and then transferred to a growth chamber at a diurnal temperature cycle gradually changing from $4^{\circ} \mathrm{C}$ at 2:00 a.m. to $20^{\circ} \mathrm{C}$ at 2:00 p.m. with a daily 16 -h photoperiod.

\section{Spot blotch inoculation.}

The second leaves of seedling were inoculated with spot blotch (C. sativus) isolate ND85F (100 $\mu$ l of a suspension of 5,000 conidia/ml) and kept at $100 \%$ humidity overnight. The following day, plants were transferred to growth chambers and grown for 7 days prior to disease phenotyping and analysis.

\section{Protein kinase inhibitor assays.}

Plants of resistant cv. Morex were treated separately with 5$\mu \mathrm{M}$ concentration of staurosporin, $\mathrm{H} 7, \mathrm{~A} 7, \mathrm{~A} 8$, or $\mathrm{H} 8$, or 2.5$\mu \mathrm{M}$ concentrations of K252a or K252b, all from Sigma-Aldrich. The inhibitors were applied to the leaf surface and allowed to dry for $15 \mathrm{~min}$ and then inoculated with the avirulent stem rust race, MCCF. Samples were collected 15 min postinoculation and subjected to RPG1 phosphorylation assay or were scored for disease reaction on the 14th day after inoculation.

\section{Phosphoimmunoprecipitation and Western blot analysis.}

Approximately $200 \mu \mathrm{g}$ of leaf tissue was ground in $500 \mu \mathrm{l}$ of ice-cold extraction buffer $(0.5 \mathrm{M}$ sorbitol, $50 \mathrm{mM}$ Tris $\mathrm{HCl}$ [pH 7.5], $10 \mathrm{mM} \mathrm{MgCl}_{2}$, and $1 \mathrm{mM}$ dithiothreitol [DTT]). Cell debris was removed by centrifugation at $15,300 \times g$ for 10 min, and total protein remaining in the supernatant was quantified by a dye-binding assay according to the manufacturer's instructions (Bio-Rad, Hercules, CA, U.S.A.). For phosphoimmunoprecipitation, $500 \mu \mathrm{g}$ of total protein was combined with $20 \mu \mathrm{l}$ of either phosphothreonine-specific (mono-anti-phosphothreonine ascites, catalog no. PTHR 12-M) or phosphoserine-specific (mono anti-phosphoserine immunoglobulin $\mathrm{G}$, catalog no. PSER12-M) antibodies (Alpha Diagnostics, Austin, TX, U.S.A.) separately in extraction buffer and $500 \mu \mathrm{l}$ of $2 \times$ immunoprecipitation buffer $(1 \mathrm{M} \mathrm{KCl}, 0.02 \mathrm{M}$ EDTA, and $2 \mathrm{mM}$ PMSF) and rotated end-over-end at $4^{\circ} \mathrm{C}$ for $12 \mathrm{~h}$. Protein A-agarose $(30 \mu \mathrm{l})$ (Invitrogen, La Jolla, CA, U.S.A.) was added and incubated on ice for $1 \mathrm{~h}$ to precipitate the immuno- complexes, which were collected at $15,300 \times \mathrm{g}$. Immunocomplexes were washed four times with $1 \mathrm{ml}$ of ice-cold immunoprecipitation buffer, resuspended in $30 \mu \mathrm{l}$ of Laemmli sample buffer, boiled at $95^{\circ} \mathrm{C}$ for $3 \mathrm{~min}$, and analyzed by sodium dodecyl sulfate polyacrylamide gel electrophoresis (SDS-PAGE). Proteins were electroblotted to polyvinylidene difluoride (PVDF) membranes and blocked in Tris-buffered salineTween (TBST) (20 mM Tris, $500 \mathrm{mM} \mathrm{NaCl}$, and $0.1 \%$ Tween20 [pH 7.5]) containing $10 \%$ nonfat dry milk. The blots were reacted with RPG1-specific polyclonal antibodies (Nirmala et al. 2007) for $12 \mathrm{~h}$ at room temperature and then with horseradish peroxidase-conjugated secondary antibodies (Alpha Diagnostics). Bands were visualized with the Nu Glo chemiluminescent detection system according to the manufacturer's directions (Alpha Diagnostics).

\section{RPG1 immunoprecipitation and Western blot analysis.}

Approximately $200 \mu \mathrm{g}$ of leaf tissue was ground in $500 \mu \mathrm{l}$ of ice-cold extraction buffer $(0.5 \mathrm{M}$ sorbitol, $50 \mathrm{mM}$ Tris $\mathrm{HCl}$ [pH 7.5], $10 \mathrm{mM} \mathrm{MgCl}$, and $1 \mathrm{mM}$ DTT). In total, $5 \mu \mathrm{l}$ of the phosphatase inhibitor cocktail 3 (catalog no. P0044) from Sigma-Aldrich was included in the extraction buffer for every $200 \mu \mathrm{g}$ of leaf tissue ground. Cell debris was removed by centrifugation at $15,300 \times g$ for $10 \mathrm{~min}$, and total protein remaining in the supernatant was quantified by a dye-binding assay according to the manufacturer's instruction (Bio-Rad). For RPG1 immunoprecipitation, $500 \mu \mathrm{g}$ of total protein was combined with $30 \mu$ of affinity-purified RPG1 antibody in extraction buffer and $500 \mu \mathrm{l}$ of $2 \times$ immunoprecipitation buffer ( $1 \mathrm{M}$ $\mathrm{KCl}, 0.02 \mathrm{M}$ EDTA, and $2 \mathrm{mM}$ PMSF) and rotated end-overend at $4{ }^{\circ} \mathrm{C}$ for $12 \mathrm{~h}$. Protein A-agarose (30 $\left.\mu \mathrm{l}\right)$ (Invitrogen) was added and incubated on ice for $1 \mathrm{~h}$ to precipitate the immunocomplexes, which were collected at 15,300 $\times$ g. Immunocomplexes were washed four times with $1 \mathrm{ml}$ of ice-cold immunoprecipitation buffer, resuspended in $30 \mu \mathrm{l}$ of Laemmli sample buffer, boiled at $95^{\circ} \mathrm{C}$ for $3 \mathrm{~min}$, and analyzed by SDS-PAGE. Proteins were electroblotted to PVDF membranes and blocked in TBST (20 mM Tris, $500 \mathrm{mM} \mathrm{NaCl}$, and 0.1\% Tween-20 [pH 7.5]) containing $10 \%$ nonfat dry milk. The blots were reacted with either phosphoserine-, phosphothreonine- or RPG1specific antibodies for $12 \mathrm{~h}$ at room temperature and then with horseradish peroxidase-conjugated secondary antibodies (Alpha Diagnostics). Bands were visualized with the $\mathrm{Nu}$ Glo chemiluminescent detection system according to the manufacturer's directions (Alpha Diagnostics).

\section{ACKNOWLEDGMENTS}

Research was supported by the National Research Initiative of the United States Department of Agriculture Co-operative State Research, Education, and Extension Service grant no. 2007-35301-18205 and National Institute of Food and Agriculture grant no. 2010-65108-20568.

\section{LITERATURE CITED}

Aaronson, D. S., and Horvath, C. M. 2002. A road map for those who don't know JAK-STAT. Science 296:1653-1655.

Asai, T., Tena, G., Plotnikova, J., Willmann, M. R., Chiu, W.-L., GomezGomez, L., Boller, T., Ausubel, F. M., and Sheen, J. 2002. MAP kinase signalling cascade in Arabidopsis innate immunity. Nature 415:977-983.

Benschop, J. J., Mohammed, S., O’Flaherty, M., Heck, A. J. R., Slijper, M., and Menke, F. L. H. 2007. Quantitative phosphoproteomics of early elicitor signaling in Arabidopsis. Mol. Cell Proteomics 6:1198-1214.

Blatt, M. R., Grabov, A., Brearley, J., Hammond-Kosack, K., and Jones, J. D. G. 1999. $\mathrm{K}+$ channels of $C f-9$ transgenic tobacco guard cells as targets for Cladosporium fulvum Avr9 elicitor-dependent signal transduction. Plant J. 19:453-462.

Boyes, D. C., Nam, J., and Dangl, J. L. 1998. The Arabidopsis thaliana $R P M 1$ disease resistance gene product is a peripheral plasma membrane protein that is degraded coincident with the hypersensitive response. 
Proc. Natl. Acad. Sci. U.S.A. 95:15849-15854.

Brueggeman, R., Rostoks, N., Kudrna, D., Kilian, A., Han, F., Chen, J., Druka, A., Steffenson, B., and Kleinhofs, A. 2002. The barley stem rustresistance gene $R p g 1$ is a novel disease-resistance gene with homology to receptor kinases. Proc. Natl. Acad. Sci. U.S.A. 99:9328-9333.

Brueggeman, R., Druka, A., Nirmala, J., Cavileer, T., Drader, T., Rostoks, N., Mirlohi, A., Bennypaul, H., Gill, U., Kudrna, D., Whitelaw, C., Kilian, A., Han, F., Sun, Y., Gill, K., Steffenson, B., and Kleinhofs, A. 2008. The stem rust resistance gene Rpg5 encodes a novel protein with nucleotide binding site, leucine-rich and protein kinase domains. Proc. Natl. Acad. Sci. U.S.A. 105:14970-14975.

Catanzariti, A.-M., Dodds, P. N., Lawrence, G. J., Ayliffe, M. A., and Ellis, J. G. 2006. Haustorially expressed secreted proteins from flax rust are highly enriched for avirulence elicitors. Plant Cell 18:243-256.

Chinchilla, D., Zipfel, C., Robatzek, S., Kemmerling, B., Nurnberger, T. Jones, J. D. G., Felix, G., and Boller, T. 2007. A flagellin-induced complex of the receptor FLS2 and BAK1 initiates plant defence. Nature 448:497-500.

de Wit, J. G. M., Mehrabi, R., van den Burg, H. A., and Stergiopoulos, I. 2009. Fungal effector proteins: Past, present and future. Mol. Plant Pathol. 10:735-747.

Dietrich, A., Mayer, J. E., and Hahlbrock, K. 1990. Fungal elicitor triggers rapid, transient, and specific protein phosphorylation in parsley cell suspension cultures. J. Biol. Chem. 265:6360-6368.

Dodds, P. N., Lawrence, G. J., Catanzariti, A.-M., Ayliffe, M., and Ellis, J. 2004. The Melampsora lini AvrL567 avirulence genes are expressed in haustoria and their products are recognized inside plant cells. Plant Cell 16:755-768

Durek, P., Schmidt, R., Heazlewood, J. L., Jones, A., MacLean, D., Nagel, A., Kersten, B., and Schulze, W. X. 2010. PhosPhAt: The Arabidopsis thaliana phosphorylation site database. An update. Nucleic Acids Res. 38:D828-D834.

Felix, G., Grosskopf, D. G., Regenass, M., and Boller, T. 1991. Rapid changes of protein phosphorylation are involved in transduction of the elicitor signal in plant cells. Proc. Natl. Acad. Sci. U.S.A. 88:88318834.

Flor, H. H. 1971. Current status of the gene-for-gene concept. Annu. Rev. Phytopathol. 9:275-296.

Fu, D., Uauy, C., Distelfeld, A., Blechl, A., Epstein, L., Chen, X., Sela, H., Fahima, T., and Dubcovsky, J. 2009. A kinase-START gene confers temperature-dependent resistance to wheat stripe rust. Science 323:13571360.

Gohre, V., and Robatzek, S. 2008. Breaking the barriers: Microbial effector molecules subvert plant immunity. Annu. Rev. Phytopathol. 46:189-215.

Grimsrud, P. A., den Os, D., Wenger, C. D., Swaney, D. L., Schwartz, D., Sussman, M. R., Ane, J.-M., and Coon, J. J. 2010. Large-scale phosphoprotein analysis in Medicago truncatula roots provides insight into in vivo kinase activitry in legumes. Plant Physiol. 152:19-28.

Hammond-Kosack, K. E., and Jones, J. D. G. 1997. Plant disease resistance genes. Annu. Rev. Plant Physiol. Plant Mol. Biol. 48:575-607.

Heese, A., Ludwig, A. A., and Jones, J. D. G. 2005. Rapid phosphorylation of a syntaxin during the Avr $9 / C f$-9-race-specific signaling pathway. Plant Physiol. 138:2406-2416.

Hoefle, C., and Huckelhoven, R. 2008. Enemy at the gates: Traffic at the plant cell pathogen interface. Cell. Microbiol. 10:2400-2407.

Horvath, H., Rostoks, N., Brueggeman, R., Steffenson, B., von Wettstein, D., and Kleinhofs, A. 2003. Genetically engineered stem rust resistance in barley using the Rpg1 gene. Proc. Natl. Acad. Sci. U.S.A. 100:364-369.

Jones, J. D. G., and Dangl, J. L. 2006. The plant immune system. Nature 444:323-329.

Kleinhofs, A., Brueggeman, R., Nirmala, J., Zhang, L., Mirlohi, A., Druka, A., Rostoks, N., and Steffenson, B.J. 2009. Barley stem rust resistance genes: Structure and function. Plant Genome 2:109-120.

Ligterink, W., Kroj, T., zur Nieden, U., Hirt, H., and Scheel, D. 1997. Receptor-mediated activation of a MAP kinase in pathogen defense of plants. Science 276:2054-2057.

Mansfield, J. D. 2009. From bacterial avirulence genes to effector functions via the hrp delivery system: An overview of 25 years of progress in our understanding of plant innate immunity. Mol. Plant Pathol. 10:721-734.

Martin, G. M., Brommonschenkel, S. H., Chunwongse, J., Frary, A., Ganal, M. W., Spivey, R., Wu, T., Earle, E. D., and Tanksley, S. D. 1993. Mapbased cloning of a protein kinase gene conferring disease resistance in tomato. Science 262:1432-1436.

Mirlohi, A., Brueggeman, R., Drader, T., Nirmala, J., Steffenson, B. J., and Kleinhofs, A. 2008. Allele sequencing of the barley stem rust resistance gene Rpg1 identifies regions relevant to disease resistance. Phytopathology 98:910-918.

Nakagami, H., Sugiyama, N., Mochida, K., Daudi, A., Yoshida, Y., Toyoda,
T., Tomita, M., Ishihama, Y., and Shirasu, K. 2010. Large-scale comparative phosphoproteomics identifies conserved phosphorylation sites in plants. Plant Physiol. 153:1161-1174.

Nam, K. H., and Li, J. 2002. BRI1/BAK1, a receptor kinase pair mediating brassinosteroid signaling. Cell 110:203-212.

Nirmala, J., Brueggeman, R., Maier, C., Clay, C., Rostoks, N., Kannangara, C. G., von Wettstein, D., Steffenson, B., and Kleinhofs, A. 2006. Subcellular localization and functions of the barley stem rust resistance receptor-like serine/threonine-specific protein kinase Rpg1. Proc. Natl. Acad. Sci. U.S.A. 103:7518-7523.

Nirmala, J., Dahl, S., Steffenson, B. J., Kannangara, C. G., von Wettstein, D., Chen, X., and Kleinhofs, A. 2007. Proteolysis of the barley receptor-like protein kinase RPG1 by a proteasome pathway is correlated with $R p g 1$-mediated stem rust resistance. Proc. Natl. Acad. Sci. U.S.A. 104:10276-10281.

Nuhse, T. S., Bottrill, A. R., Jones, A. M. E., and Peck, S. C. 2007. Quantitative phosphoproteomics analysis of plasma membrane proteins reveals regulatory mechanisms of plant innate immune responses. Plant $\mathrm{J}$. 51:931-940.

O'Shea, J. J., and Leonard, W. J. 1998. Jaks and STATs: Biological implications. Annu. Rev. Immunol. 16:293-322.

Piedras, P., Hammond-Kosack, K. E., Harrison, K., and Jones, J. D. G 1998. Rapid, $C f$-9-and Avr9-dependent production of active oxygen species in tobacco suspension cultures. Mol. Plant-Microbe Interact. 11:1155-1166.

Richberg, M. H., Aviv, D. H., and Dangl, J. L. 1998. Dead cells do tell tales. Curr. Opin. Plant Biol. 1:480-485.

Romeis, T., Piedras, P., Zhang, S., Klessig, D. F., Hirt, H., and Jones, J. D. G. 1999. Rapid Avr9- and Cf-9-dependent activation of MAP kinases in tobacco cell cultures and leaves: Convergence of resistance gene, elicitor, wound, and salicylate responses. Plant Cell 11:273-287.

Romeis, T., Piedras, P., and Jones, J. D. G. 2000. Resistance gene-dependent activation of a calcium-dependent protein kinase in the plant defense response. Plant Cell 12:803-815.

Rostoks, N., Steffenson, B. J., and Kleinhofs, A. 2004. Structure and expression of the barley stem rust resistance gene Rpg1. Physiol. Mol. Plant Pathol. 64:91-101.

Scheel, D. 1998. Resistance response physiology and signal transduction. Curr. Opin. Plant Biol. 1:305-310.

Sellam, M. A., and Wilcoxson, R. D. 1976. Development of Puccinia graminis f. sp. tritici on resistant and susceptible barley cultivars. Phytopathology 66:667-668.

Song, W.-Y., Wang, G.-L., Chen, L.-L., Kim, H.-S., Pi, L.-Y., Gardner, J., Holsten, T., Wang, B., Zhai, W.-X., Zhu, L.-H., Fauquet, C., and Ronald, P. 1995. A receptor kinase-like protein encoded by the rice disease resistance gene, Xa21. Science 270:1804-1806.

Steffenson, B. J. 1992. Analysis of durable resistance to stem rust in barley. Euphytica 63:153-167.

Stergiopoulos, I., and de Wit, P. J. G. M. 2009. Fungal effector proteins. Annu. Rev. Phytopathol. 47:233-263.

Swiderski, M. R., and Innes, R. W. 2001. The Arabidopsis PBS1 resistance gene encodes a member of a novel protein kinase subfamily. Plant $\mathrm{J}$. 26:101-112.

van der Hoorn, R. A. L., and Kamoun, S. 2008. From guard to decoy: A new model for perception of plant pathogen effectors. Plant Cell 20:2009-2017.

Vera-Estrella, R., Blumwald, E., and Higgins, V. J. 1992. Effect of specific elicitors of Cladosporium fulvum on tomato suspension cells. Plant Physiol. 99:1208-1215.

Wang, X.-J., Goshe, M. B., Soderblom, E. J., Phinney, B. S., Kuchar, J. A., Li, J., Asami, T., Yoshida, S., Huber, S. C., and Clouse, S. D. 2005 Identification and functional analysis of in vivo phosphorylation sites of the Arabidopsis BRASSINOSTEROID-INSENSITIVE1 receptor kinase. Plant Cell 17:1685-1703.

Yang, Y., Shah, J., and Klessig, D. F. 1997. Signal perception and transduction in plant defense responses. Genes Dev. 11:1621-1630.

Zhang, L., Fetch, T., Nirmala, J., Schmierer, D., Brueggeman, R., Steffenson, B., and Kleinhofs, A. 2006. Rpr1, a gene required for Rpg1-dependent resistance to stem rust in barley. Theor. Appl. Genet. 113:847-855.

Zhang, S., and Klessig, D. F. 1998a. Resistance gene $N$-mediated de novo synthesis and activation of a tobacco mitogen-activated protein kinase by tobacco mosaic virus infection. Proc. Natl. Acad. Sci. U.S.A. 95:7433-7438.

Zhang, S., and Klessig, D. F. 1998b. The tobacco wounding-activated mitogen-activated protein kinase is encoded by SIPK. Proc. Natl. Acad. Sci. U.S.A. 95:7225-7230

Zhang, S., Du, H., and Klessig, D. F. 1998. Activation of the tobacco SIP kinase by both a cell wall-derived carbohydrate elicitor and purified proteinaceous elicitins from Phytophtora spp. Plant Cell 10:435-449. 